\title{
Is Concurrent Chemotherapy With Radiotherapy for Esophageal Cancer Beneficial in Patients Aged 80 Years or Older?
}

\author{
KEIICHI JINGU ${ }^{1}$, NORIYOSHI TAKAHASHI ${ }^{1}$, YUJI MURAKAMI ${ }^{2}$, KAZUKI ISHIKAWA $^{3}$, \\ SATOSHI ITASAKA $^{4}$, TAKEO TAKAHASHI ${ }^{5}$, FUMIAKI ISOHASHI ${ }^{6}$, TORU SAKAYAUCHI ${ }^{7}$, \\ KAZUHIKO OGAWA ${ }^{6}$ and JROSG Working Subgroup of Gastrointestinal Cancers
}

\author{
${ }^{1}$ Department of Radiation Oncology, Tohoku University Graduate School of Medicine, Sendai, Japan; \\ ${ }^{2}$ Department of Radiation Oncology, Hiroshima University Graduate School of Medicine, Hiroshima, Japan; \\ ${ }^{3}$ Department of Radiation Oncology, Kindai University Faculty of Medicine, Osaka, Japan; \\ ${ }^{4}$ Department of Radiation Oncology, Kurashiki Central Hospital, Kurashiki, Japan; \\ ${ }^{5}$ Department of Radiation Oncology, Saitama Medical Center, Saitama Medical University, Kawagoe, Japan; \\ ${ }^{6}$ Department of Radiation Oncology, Osaka University Graduate School of Medicine, Osaka, Japan; \\ ${ }^{7}$ Department of Radiation Oncology, Osaki Citizen Hospital, Osaka, Japan
}

\begin{abstract}
Background/Aim: To determine whether concurrent chemotherapy with radiotherapy should be performed in elderly patients with esophageal cancer. Patients and Methods: A total of 185 patients aged 80 years or older who were treated with definitive radiotherapy alone or combined with chemoradiotherapy for esophageal cancer at seven institutions were enrolled. In order to compare survival rates of patients treated with chemoradiotherapy with those of patients treated with radiotherapy alone, propensity score matching was performed to homogenize the two populations. Results: For the whole patient cohort, the 3-year overall survival (OS) rate was $52.6 \%$ and the median survival was 42.5 months. After propensity score matching, the 3-year OS rate for the chemoradiotherapy group was not significantly better than that for the group treated with radiotherapy alone (53.7\% vs. 59.9\%, $p=0.876)$. Conclusion: Concurrent chemotherapy with radiotherapy for esophageal cancer in patients aged 80 years or older did not have significant $O S$ benefit over radiotherapy alone.
\end{abstract}

Esophageal cancer is the fifth most common cause of cancerrelated death worldwide for men and the eighth most common cause of cancer-related death worldwide for women (1). Since

This article is freely accessible online.

Correspondence to: Keiichi Jingu, MD, Ph.D., Department of Radiation Oncology, Tohoku University Graduate School of Medicine, 1-1 Seiryochou, Aoba-ku, Sendai 980-8574, Japan. Tel: +81 227177312, Fax: +81 227177316, e-mail: kjingu-jr@rad.med.tohoku.ac.jp

Key Words: Concurrent chemotherapy, esophageal cancer, elderly. the Radiation Therapy Oncology Group (RTOG) 85-01 trial showed that the outcome of definitive chemoradiotherapy was significantly better than that of radiotherapy alone for patients with esophageal cancer (2), concurrent chemoradiotherapy has been a standard treatment for esophageal cancer. However, most patients aged 80 years or older are unlikely to be able to tolerate chemotherapy. There are about 4,000 patients aged 80 years or older with esophageal cancer in Japan every year. Miyata et al. reported that elderly patients aged 80 years or older who underwent surgery for esophageal cancer had a poorer prognosis than did younger patients because a smaller percentage of elderly patients received neoadjuvant therapy (3). They concluded that aggressive treatment may be recommended for elderly patients. Based on data from Surveillance, Epidemiology, and End Results (SEER), patients aged 80 years or older with esophageal cancer benefit from radiotherapy alone compared to no radiotherapy if the cancer is in a localized/regional stage (4). The results of analysis of data in a Japanese nationwide database showed that radiotherapy alone tended to be performed for elderly patients (5). There is no definitive evidence of a beneficial effect of concurrent chemotherapy with radiotherapy for elderly patients with esophageal cancer. The purpose of the present study was to determine whether concurrent chemotherapy with radiotherapy rather than radiotherapy alone should be administered to patients with esophageal cancer aged 80 years or older.

\section{Patients and Methods}

Patient eligibility. The eligibility criteria included i) histopathologically proven esophageal cancer; ii) clinical stage T1-4; N0-1; M0/M1 lym [International Union Against Cancer (UICC) 2002)] (6); iii) 80 or more years of age; iv) no history of radiotherapy for 
Table I. Characteristics of the whole patient cohort $(n=185)$.

\begin{tabular}{|c|c|}
\hline Characteristic & \\
\hline \multicolumn{2}{|l|}{ Age, years } \\
\hline Mean \pm SD & $83.3 \pm 33.2$ \\
\hline \multicolumn{2}{|l|}{ Gender, $\mathrm{n}$} \\
\hline Male:female & $144: 41$ \\
\hline \multicolumn{2}{|l|}{ ECOG PS, n } \\
\hline 0 & 62 \\
\hline 1 & 92 \\
\hline 2 & 31 \\
\hline \multicolumn{2}{|l|}{$\mathrm{TNM}^{*}, \mathrm{n}$} \\
\hline I & 52 \\
\hline II & 65 \\
\hline III & 57 \\
\hline IV & 11 \\
\hline \multicolumn{2}{|c|}{ Median observation period (range), months } \\
\hline All & $19.1(0.8-92.8)$ \\
\hline Survivors & $25.2(1.0-92.8)$ \\
\hline \multicolumn{2}{|l|}{ Primary site, $\mathrm{n}$} \\
\hline $\mathrm{Ce}$ & 11 \\
\hline Ut & 30 \\
\hline Mt & 94 \\
\hline $\mathrm{Lt}$ & 44 \\
\hline $\mathrm{Ae}$ & 6 \\
\hline \multicolumn{2}{|l|}{ Irradiation dose, Gy } \\
\hline Median (range) & $60(10.0-70.0)$ \\
\hline \multicolumn{2}{|l|}{ Irradiation field, $\mathrm{n}$} \\
\hline Elective nodal & 105 \\
\hline Involved & 80 \\
\hline \multicolumn{2}{|l|}{ Concurrent chemotherapy, $\mathrm{n}$} \\
\hline Yes & 79 \\
\hline No & 106 \\
\hline \multicolumn{2}{|l|}{ Histopathology, $\mathrm{n}$} \\
\hline Squamous cell carcinoma & 177 \\
\hline Adenocarcinoma & 7 \\
\hline Basaloid carcinoma & 1 \\
\hline
\end{tabular}

ECOG PS: Eastern Cooperative Oncology Group performance status; *Union for International Cancer Control 2002 (6).

the chest; v) Eastern Cooperative Oncology Group performance status (ECOG PS) of 2 or less; vi) no other active malignant tumor; and vii) absence of severe lung; heart or liver disorder.

Data for 185 patients (144 males and 41 females) who received definitive radiotherapy with or without concurrent chemotherapy between 2004 and 2014 at seven institutions which took part in the Japanese Radiation Oncology Study Group (JROSG) Working Subgroup of Gastrointestinal Cancers were used for analysis in this retrospective study.

Toxicity. Toxicity was graded according to the Common Terminology Criteria for Adverse Events (CTCAE v4.0) (7). The grade was scored retrospectively based on the clinical chart. An adverse effect at more than 90 days after completion of radiotherapy was defined as late toxicity.

Statistics. Survival estimates were calculated using the KaplanMeier method from the first date of radiotherapy, and differences were evaluated by the log-rank test.

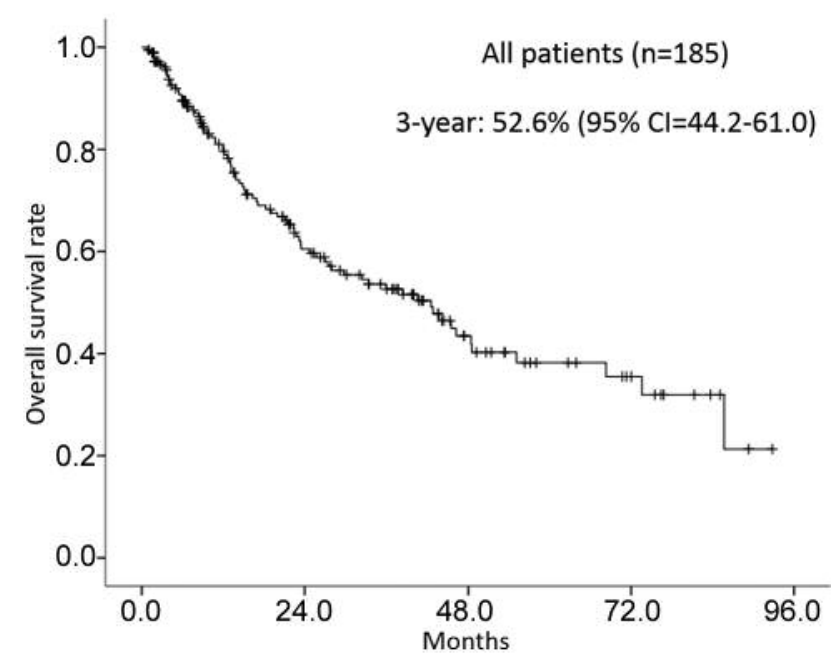

Figure 1. Overall survival curve considering all patients aged 80 years or older with esophageal cancer (Kaplan-Meier method).

Propensity scores were calculated with gender, age, stage (UICC 2002), performance status, institution and histology. Patients who received chemoradiotherapy (CRT group) and patients who received radiotherapy alone (RT alone group) were matched with a propensity score of less than 0.1 . A $p$-value of less than 0.05 was considered significant. All analyses were performed using the SPSS 22.0 software package (IBM, Armonk, NY, USA).

Ethics. This retrospective study was approved by the Ethical Committees at all Institutions.

\section{Results}

The characteristics of all patients $(n=185)$ are shown in Table I. Ten patients could not complete the planned radiotherapy because of toxicities. Seventy-nine of the 185 patients received concurrent chemoradiotherapy. The chemotherapeutic regimens were cisplatin plus 5-fluorouracil $(5-\mathrm{FU})(\mathrm{n}=34)$, nedaplatin plus 5-FU ( $n=19)$, nedaplatin plus docetaxel $(n=9), S-1$ alone $(n=4)$, docetaxel alone $(n=5), 5-F U$ alone $(n=6)$, carboplatin alone $(n=1)$ and cisplatin alone $(n=1)$. There were 81 deaths including 22 deaths from other causes. Considering all patients, the 3 -year overall survival (OS) rate was $52.6 \%$ (95\% confidence interval $(C I)=44.2-61.0 \%)$ and the median survival period was 42.5 months (Figure 1). Forty-four patients had late toxicities of grade 2 or more, including five with grade 5 (four with radiation pneumonitis and one with cardiac failure). Although the 3-year OS rate $[58.8 \%(95 \% \mathrm{CI}=47.2-70.4 \%$ versus $46.5 \%(95 \%$ $\mathrm{CI}=34.3-58.7 \%) ; p=0.124]$, 3-year cause-specific survival (CSS) rate $[68.3 \%(95 \% \mathrm{CI}=56.9-79.7 \%)$ versus $55.5 \%(95 \%$ $\mathrm{CI}=42.6-68.4 \%) ; p=0.194]$ and 3-year progression-free survival (PFS) rate $[39.9 \%(95 \% \mathrm{CI}=28.5-51.3 \%)$ versus $26.0 \%(95 \%$ $\mathrm{CI}=15.6-36.4 \%) ; p=0.073]$ were higher in patients treated with 
Table II. Characteristics of patients in each group after propensity score matching.

\begin{tabular}{|c|c|c|}
\hline Characteristic & $\begin{array}{l}\text { CRT } \\
(n=51)\end{array}$ & $\begin{array}{c}\text { RT alone } \\
(\mathrm{n}=51)\end{array}$ \\
\hline \multicolumn{3}{|l|}{ Age, years } \\
\hline Mean \pm SD & $82.2 \pm 1.8$ & $82.2 \pm 2.0$ \\
\hline \multicolumn{3}{|l|}{ Gender, $\mathrm{n}$} \\
\hline Male:female & $43: 8$ & $40: 11$ \\
\hline \multicolumn{3}{|l|}{ ECOG PS, $\mathrm{n}$} \\
\hline 0 & 21 & 16 \\
\hline 1 & 24 & 31 \\
\hline 2 & 6 & 4 \\
\hline \multicolumn{3}{|l|}{ TNM, $\mathrm{n} *$} \\
\hline I & 15 & 18 \\
\hline II & 16 & 15 \\
\hline III & 16 & 15 \\
\hline IV & 4 & 3 \\
\hline \multicolumn{3}{|l|}{ Observation period, months } \\
\hline Median (range) & $23.4(1.8-92.8)$ & $13.9(1.5-83.7)$ \\
\hline \multicolumn{3}{|l|}{ Institution, $\mathrm{n}^{\ddagger}$} \\
\hline $\mathrm{a}$ & 14 & 26 \\
\hline $\mathrm{b}$ & 13 & 10 \\
\hline c & 2 & 6 \\
\hline $\mathrm{d}$ & 6 & 3 \\
\hline $\mathrm{e}$ & 4 & 2 \\
\hline $\mathrm{f}$ & 10 & 1 \\
\hline $\mathrm{g}$ & 2 & 3 \\
\hline \multicolumn{3}{|l|}{ Irradiation dose, Gy } \\
\hline Median (range) & $60(50-70)$ & $64(59.4-70)$ \\
\hline \multicolumn{3}{|l|}{ Irradiation field, $\mathrm{n}$} \\
\hline Elective nodal & 31 & 32 \\
\hline Involved & 20 & 19 \\
\hline \multicolumn{3}{|l|}{ Planned RT, n } \\
\hline Complete & 49 & 50 \\
\hline Incomplete & 2 & 1 \\
\hline \multicolumn{3}{|l|}{ Histopathology, $\mathrm{n}$} \\
\hline Squamous cell carcinoma & 50 & 47 \\
\hline Adenocarcinoma & 1 & 4 \\
\hline
\end{tabular}

ECOG PS: Eastern Cooperative Oncology Group performance status CRT: chemoradiotherapy; RT: radiotherapy. *Union for International Cancer Control 2002 (6). $¥$ Anonymized.

chemoradiotherapy than in patients treated with radiotherapy alone, the differences were not significant (Figure 2).

After propensity score matching, the groups treated with RT alone or CRT each included 51 paired patients. The characteristics of patients in each group are shown in Table II. There were no significant differences between the groups in 3year OS rate $[53.7 \%(95 \% \mathrm{CI}=38.6-68.8 \%)$ versus $59.9 \%(95 \%$ $\mathrm{CI}=42.3-77.5 \%), p=0.876], 3$-year CSS rate $[67.2 \%(95 \%$ $\mathrm{CI}=52.1-82.3 \%)$ versus $61.1 \% \quad(95 \% \quad \mathrm{CI}=43.3-78.9 \%)$, $p=0.571]$ and 3-year PFS rate $[35.9 \%(95 \% \mathrm{CI}=21.6-50.2 \%)$ versus $26.6 \%$ (95\% $\mathrm{CI}=11.1-42.1 \%$ ), $p=0.259$ ] (Figure 3). One patient in the group treated with RT alone and two in the CRTtreated group could were unable to complete the planned radiotherapy. Seven patients in the group treated with RT alone
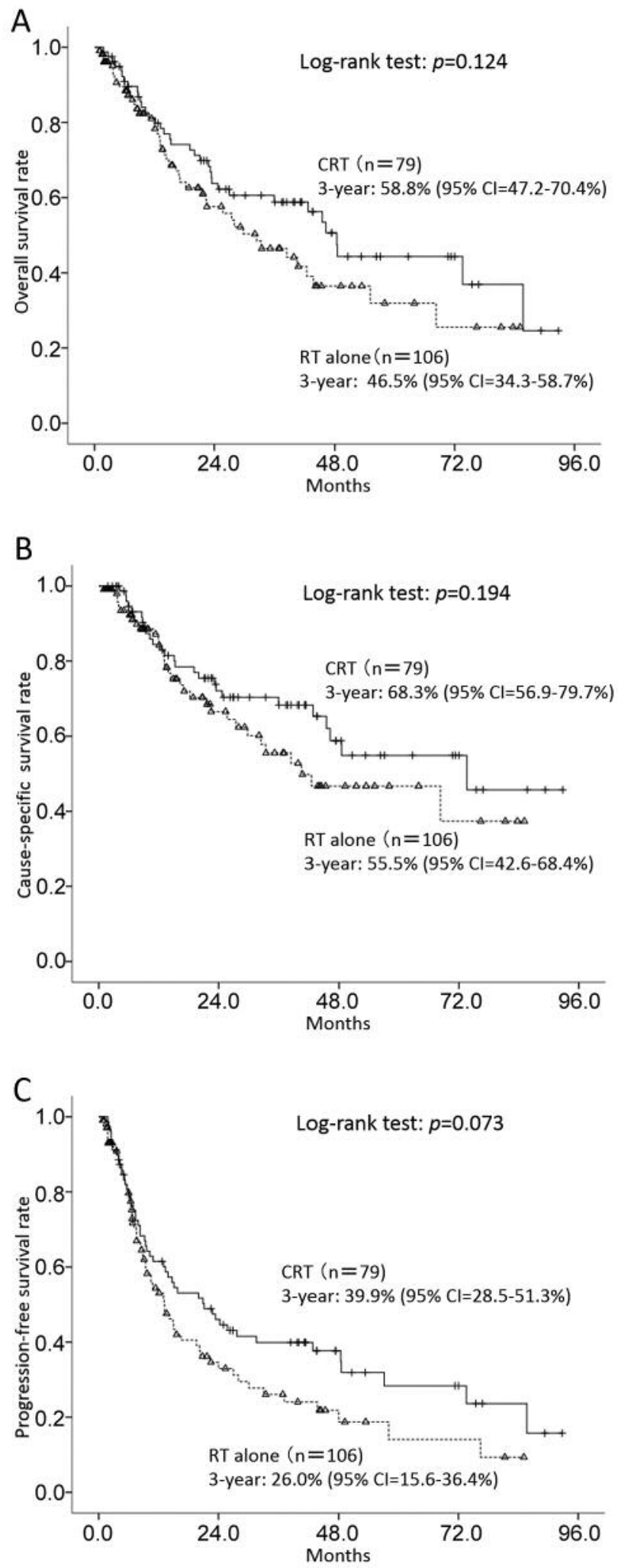

Figure 2. Curves for overall (A), cause-specific (B), and progressionfree $(C)$ survival in patients treated with chemoradiotherapy $(n=79)$ and patients treated with radiotherapy alone $(n=106)$ before propensity score matching (Kaplan-Meier method). 
Table III. Late toxicities in each group after propensity score matching.

\begin{tabular}{lcccc}
\hline & \multicolumn{4}{c}{ Toxicity, $\mathrm{n} *$} \\
\cline { 2 - 5 } Group & Grade 2 & Grade 3 & Grade 4 & Grade 5 \\
\hline CRT $(\mathrm{n}=51)$ & 13 & 2 & 1 & 2 \\
RT alone $(\mathrm{n}=51)$ & 2 & 4 & 1 & 0 \\
\hline
\end{tabular}

CRT: Chemoradiotherapy; RT: radiotherapy. ${ }^{*}$ Common Terminology Criteria for Adverse Events v4.0 (7).

and 18 in that treated with CRT had late toxicities of grade 2 or more (chi-squared test, $p=0.01$ ) (Table III).

\section{Discussion}

These findings of this study suggest that concurrent CRT for esophageal cancer did not have much meaning for patients aged 80 years or older. Concurrent chemotherapy should be performed only for appropriately selected patients, although the eligibility criteria and appropriate chemotherapeutic regimen are undefined.

Hamamoto et al. reported that only $21 \%$ of institutions selected definitive chemoradiotherapy as a treatment method for patients aged 80 years or older with esophageal cancer, although $91 \%$ of institutions selected that treatment method for patients aged 75-79 years (8). In the present study, 79 $(42.7 \%)$ out of the 185 patients received concurrent chemotherapy, and this higher proportion might be because all of the institutions that took part in this study were highvolume centers for esophageal cancer in Japan. We were unable to evaluate the difference of acute toxicities between the group treated with CRT and that treated with RT alone in this study. Eight out of the 106 patients who were treated with RT alone in this study were unable even to complete the RT, although only two out of the 79 patients who received concurrent chemotherapy did not complete the planned RT. This difference might be because patients in a poor condition were treated with RT alone. Indeed, after propensity score matching, only one patient in the group treated with RT alone was unable to complete the planned radiotherapy. Chemoradiotherapy might be performed safely in patients with a good condition, even if aged 80 years or older.

However, there were significantly more severe late toxicities in the CRT group than in that treated with RT alone in this study. Xu et al. reported that there was a particularly high incidence of pulmonary toxicity, as in the present study, in patients aged 80 years or older who received chemoradiotherapy compared with younger patients (9). Ito et $a l$. also reported that older age was found to be a risk factor for late toxicity after definitive CRT for esophageal cancer
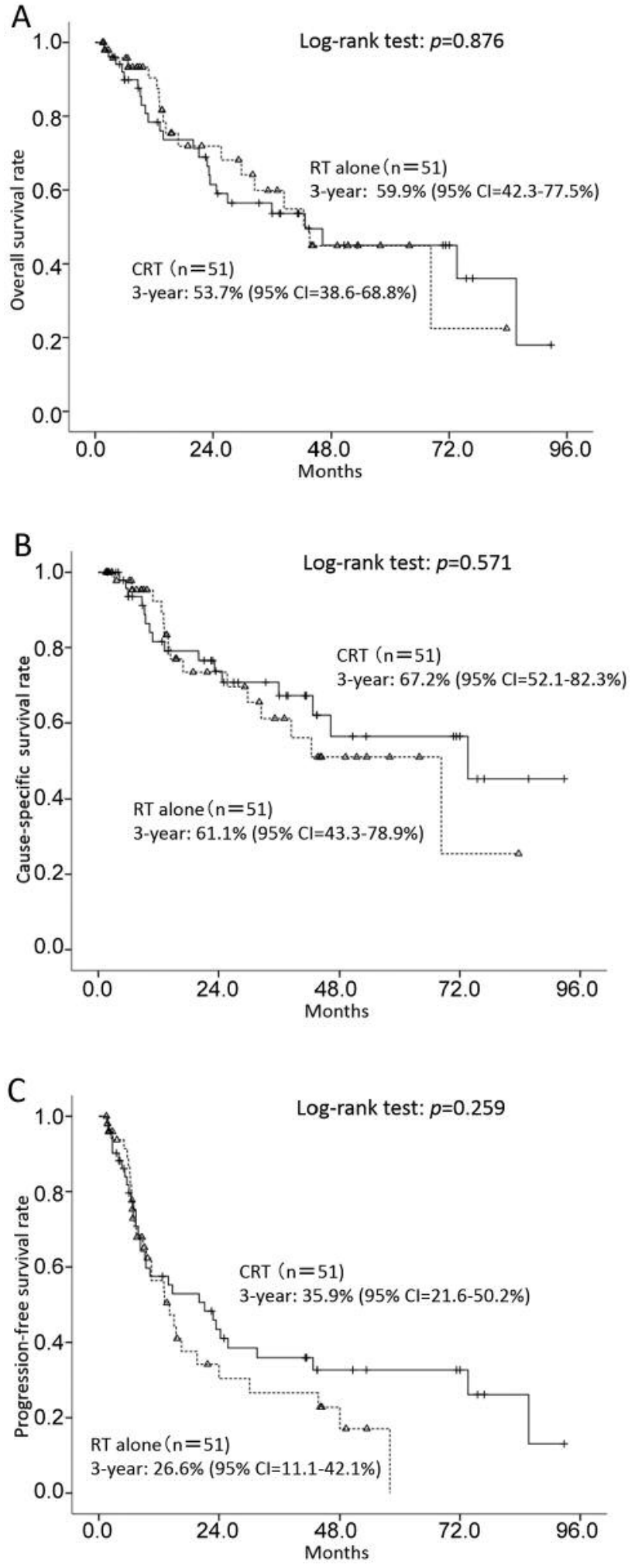

Figure 3. Curves for overall (A), cause-specific (B), and progressionfree $(C)$ survival in patients treated with chemoradiotherapy with chemoradiotherapy $(n=51)$ and patients treated with radiotherapy alone $(n=51)$ after propensity score matching (Kaplan-Meier method). 
(10). CRT should be performed with special care for patients aged 80 years or older. RT alone is considered to be relatively safe, as was indicated by the results of our study. However, even RT alone requires special attention in aged patients. The use of intensity-modulated RT was shown to be associated with significantly lower rates of all-cause mortality, cardiac mortality, and other-cause mortality in patients with esophageal cancer (11). Such new technology might be able to reduce deaths from other causes in aged patients.

In Japan, a prospective clinical study of RT for esophageal cancer in patients aged 80 years or older in multiple institutions was performed between 1992 and 2002 (12). The 3 -year OS rate in our study including patients with stage IIV (UICC 2002) was $52.6 \%$, which is better than the 3-year OS rate $(39 \%)$ in that trial, which included only patients with stage I or IIA (UICC 1997) (13). In aged patients, results of (C)RT for esophageal cancer might also be improving, although there must be a bias due to the patient volume of hospitals as described above.

There is also an issue of the irradiation field. A prospective study is needed to determine whether elective nodal irradiation or involved-field irradiation is better in elderly patients treated with RT, and which is better in elderly patients treated with CRT.

\section{Conclusion}

Our study findings suggest that concurrent CRT for esophageal cancer in elderly patients does not have a significant benefit over RT alone in terms of OS, CSS and PFS: CRT should be performed with special attention in patients aged 80 years or older.

\section{Conflicts of Interest}

There is no conflict of interest with regard to the present study.

\section{Authors' Contributions}

KJ, YM, KI, SI, TT, FI, TS and KO participated in the design of the study and performed treatment, KJ and NT collected the data and drafted the article. All Authors have read and approved the article.

\section{References}

1 Jemal A, Bray F, Center MM, Ferlay J, Ward E and Forman D: Global cancer statistics. CA Cancer J Clin 61: 69-90, 2011. PMID: 21296855. DOI: 10.3322/caac.20107

2 Cooper JS, Guo MD, Herskovic A, Macdonald JS, Martenson JA Jr., Al-Sarraf M, Byhardt R, Russell AH, Beitler JJ, Spencer S, Asbell SO, Graham MV and Leichman LL: Chemo-radiotherapy of locally advanced esophageal cancer: long-term follow-up of a prospective randomized trial (RTOG 85-01). Radiation Therapy Oncology Group. JAMA 281(17): 1623-7,1999. PMID: 10235156.
3 Miyata H, Yamasaki M, Makino T, Miyazaki Y, Takahashi T, Kurokawa Y, Nakajima K, Takiguchi S, Mori M and Doki Y: Clinical outcome of esophagectomy in elderly patients with and without neoadjuvant therapy for thoracic esophageal cancer. Ann Surg Oncol Suppl 3: S794-801, 2015. PMID: 26224407. DOI: 10.1245/s 10434-015-4769-8

4 Huang S, Zheng S, Gong T, Ma H, Ke Y, Zhao S, Wang W, Jia $\mathrm{L}$ and Zhang $\mathrm{X}$ : Survival benefit evaluation of radiotherapy in esophageal cancer patients aged 80 and older. Oncotarget $8(67)$ : 112094-112102, 2017. PMID: 29340114. DOI: 10.18632/ oncotarget.22884

5 Hamamoto Y, Sakakibara N, Nagashima F, Kitagawa Y and Higashi T: Treatment selection for esophageal cancer: Evaluation from a nationwide database. Esophagus 15(2): 109-114, 2018. PMID: 29892936. DOI: 10.1007/s 10388-018-0605-0

6 Sobin $\mathrm{LH}$ and Wittekind $\mathrm{CH}$ : International Union Against Cancer. TNM classification of malignant tumours, Wiley-Liss, New York, 2002.

7. Common Terminology Criteria for Adverse Events (CTCAE) v 4.0. Available at: http://ctep.cancer.gov/protocolDevelopment/ electronic_applications/ctc.htm\#ctc_40

8 Hamamoto Y, Akutsu Y, Nagashima F, Hironaka S, Ito Y, Kato $\mathrm{K}$, Hara H, Tsubosa Y, Nakagawa S, Daiko H, Ozawa S and Kitagawa Y: Multicenter questionnaire survey on patterns of care for elderly patients with esophageal squamous cell carcinoma by the Japan Esophageal Oncology Group. Jpn J Clin Oncol 46(2): 111-115, 2016. PMID: 26685320. DOI: $10.1093 / \mathrm{jjco} / \mathrm{hyv} 183$

9 Xu C, Xi M, Moreno A, Shiraishi Y, Hobbs BP, Huang M, Komaki R and Lin SH: Definitive chemoradiation therapy for esophageal cancer in the elderly: clinical outcomes for patients exceeding 80 years old. Int J Radiat Oncol Biol Phys 98(4): 811819, 2017. PMID: 28602412. DOI: 10.1016/j.ijrobp.2017.02.097

10 Ito H, Itasaka S, Sakanaka K, Araki N, Mizowaki T and Hiraoka M: Long-term complications of definitive chemoradiotherapy for esophageal cancer using the classical method. J Radiat Res 58(1): 106-113, 2017. PMID: 27475126. DOI: 10.1093/jrr/ rrw078

11 Lin SH, Zhang N, Godby J, Wang J, Marsh GD, Liao Z, Komaki R, Ho L, Hofstetter WL, Swisher SG, Mehran RJ, Buchholz TA, Elting LS and Giordano SH: Radiation modality use and cardiopulmonary mortality risk in elderly patients with esophageal cancer. Cancer 122(6): 917-928, 2016. PMID: 26716915. DOI: $10.1002 /$ cncr.29857

12 Kawashima M, Kagami Y, Toita T, Uno T, Sugiyama M, Tamura Y, Hirota S, Fuwa N, Hashimoto M, Yoshida H, Shikama N, Kataoka M, Akuta K, Sasaki K, Tamamoto T, Nemoto K, Ito H, Kato $\mathrm{H}$, Yamada $\mathrm{S}$ and Ikeda $\mathrm{H}$ : Prospective trial of radiotherapy for patients 80 years of age or older with squamous cell carcinoma of the thoracic esophagus. Int J Radiat Oncol Biol Phys 64(4): 1112-1121, 2006. PMID: 16376491. DOI: 10.1016/j.jirobp.2005.09.027

13 Sobin $\mathrm{LH}$ and Wittekind $\mathrm{CH}$ : International Union Against Cancer. TNM Classification of Malignant Tumours. Fifth Edition. New York: Wiley-Liss, 1997. 